\title{
Article \\ Curing Behavior of Waterborne Paint Containing Catalyst Encapsulated in Micelle
}

\begin{abstract}
Shuji Yomo
Toyota Central R\&D Labs., Inc., 41-1, Yokomichi, Nagakute, Aichi 4801192, Japan; e1463@mosk.tytlabs.co.jp; Tel.: +81-561-71-7042

Abstract: This research has studied the feasibility of fabricating a catalyst that activates at $80{ }^{\circ} \mathrm{C}$ to ensure the curing performance of two-pack isocyanate curable paints, while remaining inactive at $40{ }^{\circ} \mathrm{C}$ to ensure storage stability and pot life. The research examined whether the added dibutyl tin dilaurate (DBTL) provided a catalytic function for curing the waterborne paint, which remains almost inactive at $40{ }^{\circ} \mathrm{C}$ and activates at $80{ }^{\circ} \mathrm{C}$ or higher. It was confirmed that the use of a non-ionic surfactant with a hydrophilic-lipophilic-balance (HLB) of between 13 and 14 resulted in rapid curing at a temperature of $80{ }^{\circ} \mathrm{C}$ or higher, thereby demonstrating catalytic properties. The results also show that the viscosity of the paint remained virtually unchanged after exposure for $1 \mathrm{~h}$ at $40^{\circ} \mathrm{C}$. This wass presumed to be the result of the DBTL, which was constrained by the micelles up to a temperature of $70{ }^{\circ} \mathrm{C}$, breaking down the micelles at a temperature of $80^{\circ} \mathrm{C}$ or higher. It was also confirmed that the catalytic switching properties were not obtained at a lower or higher HLB. It was found that selecting the non-ionic surfactant by HLB can control the activating temperature of the catalytic properties.
\end{abstract}

check for updates

Citation: Yomo, S. Curing Behavior of Waterborne Paint Containing Catalyst Encapsulated in Micelle. Coatings 2021, 11, 375. https://doi.org/10.3390/ coatings11040375

Academic Editor: Ioannis V. Yentekakis

Received: 23 February 2021

Accepted: 21 March 2021

Published: 24 March 2021

Publisher's Note: MDPI stays neutral with regard to jurisdictional claims in published maps and institutional affiliations.

Copyright: (C) 2021 by the author. Licensee MDPI, Basel, Switzerland. This article is an open access article distributed under the terms and conditions of the Creative Commons Attribution (CC BY) license (https:// creativecommons.org/licenses/by/ $4.0 /)$.
Keywords: catalyst; non-ionic surfactant; micelle; waterborne paint; hydrophilic-lipophilic-balance

\section{Introduction}

Resins used for automotive body paints consist of acrylic polymers containing mainly hydroxyl groups, to ensure paint film performance, and a curing agent such as isocyanate groups or melamine resins. It is already known that reactions with acrylic polymers and isocyanates proceed slowly even at room temperature [1]. However, to ensure productivity by minimizing the length of actual painting processes, paint films are baked for a short period of time at a temperature between 140 and $160^{\circ} \mathrm{C}$, after spraying to complete the drying reaction. However, research and development are underway into ways of lowering the baking temperature as a cost-saving measure and to help reduce $\mathrm{CO}_{2}$ emissions in response to issues affecting the global environment [2]. At the same time, other research is also examining the feasibility of partially adopting plastic outer panels to reduce vehicle weight [3]. This would require the application of integrated painting and baking processes to steel body panels and plastic bumpers to lower costs and facilitate color matching between the body and bumpers [4]. In this case, the baking temperature would have to be reduced to help prevent the deformation of plastic parts. Therefore, for the reasons given above, lowering the baking temperature of paints is an extremely important topic for automotive body suppliers.

The automotive body painting process consists of layering a primer surfacer on top of electrodeposition-coated steel sheets, followed by basecoat and clearcoat paint films. The primer surfacer that forms the bottom layer of the paint film and the basecoat that forms the mid layer are both curable paints that mainly use acrylic polyols and melamine resins [5]. However, since it is extremely difficult to lower the baking temperature with a melamine resin, an isocyanate curing agent must be adopted. In contrast, the uppermost layer of the paint film is a curable paint that mainly uses acrylic polyols and isocyanates [6]. It has been proposed that blending an isocyanate curing agent with a certain amount of a 
catalyst called dibutyl tin dilaurate (DBTL) may be a feasible way of lowering the baking temperature to $100{ }^{\circ} \mathrm{C}$, while shortening the time that the baking temperature needs to be maintained [7]. However, since lowering the baking temperature would also increase reactivity at room temperature, this would likely have an adverse effect on the storage stability of the paint. To help prevent this issue, research has examined the application of masking the curing agent in advance using an isocyanate blocker such as dimethyl pyrazole or methyl ketoxime [8]. However, as the blocker is detached from the isocyanate during the baking process and evaporates in the air, this is not an optimum solution due to concerns over possible adverse environmental effects.

Therefore, this research has begun to study the feasibility of fabricating a catalyst that functionally activates at $100{ }^{\circ} \mathrm{C}$, to ensure the curing performance of two-pack isocyanate curable paints, while remaining inactive at temperatures of $40{ }^{\circ} \mathrm{C}$ or lower, to ensure storage stability and pot life. A catalyst that remains functionally inactive at temperatures of $40{ }^{\circ} \mathrm{C}$ or lower and activates at temperatures of $100{ }^{\circ} \mathrm{C}$ or higher is called a switchable catalyst. A wide range of technologies have been reported to realize these catalytic switching properties, including encapsulating the catalyst in compounds such as cyclodextrin [9-16]. For instance, Wang et al. reported smart supramolecular nano-enzymes with temperature-driven switching properties have been successfully constructed by the selfassembly of supra-amphiphiles formed by the cyclodextrin-based host-guest chemistry [9]. Although reviews have also examined the application of this approach in various industrial fields [17-21], no reports have examined its applicability to automotive paints. However, since cyclodextrin, which tends to be used for these inclusion compounds, has high hydrophilicity, it is presumed that the compounds described in these reports would not satisfy the high-performance requirements of automotive paint films.

Therefore, after examining a wide range of compounds, this research focused on the aggregates formed by non-ionic surfactant molecules in aqueous media (i.e., micelles), which suddenly break up at a certain temperature or higher (called the "cloud point"). It was proposed to take advantage of this irregular phenomenon and incorporate a catalyst into the micelles in advance to form a compound with catalytic switching properties. It has been reported that the cloud point can be freely controlled based on the structure of the non-ionic surfactant [22]. Figure 1 shows the concept of a catalyst with switchable functionality. First, this research examined the feasibility of realizing this switchable functionality (i.e., isolating (deactivating) the catalyst within the micelles in paints and low-temperature paint films, but breaking down the micelles and activating the catalyst at a certain temperature or higher). This feasibility was judged based on the curing behavior of the paint film and the paint storage stability. Next, this research examined changes in the molecular weight of the micelles caused by adding the catalyst using static light scattering (SLS), and the molecular motion of the catalyst in the surfactant aqueous solution using nuclear magnetic resonance (NMR) and heat flow of the catalyst in the surfactant solution using differential scanning calorimetry (DSC). These results were then used to discuss the mechanism of the catalytic switching function.

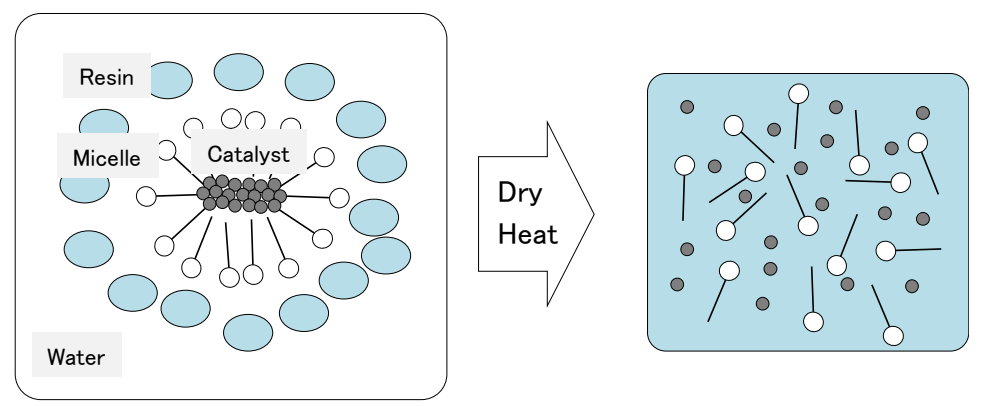

Figure 1. A catalyst encapsulated in a micelle in surfactant solution. 


\section{Materials and Methods}

\subsection{Samples of Surfactant}

The following four oleic acid non-ionic surfactants were used to realize the catalytic switching function by generating and eliminating micelles: Nonion E-205, Nonion E-212, Nonion E-215, and Nonion E-230. All surfactants were manufactured by NOF Corporation, Japan and they are abbreviated as E-205, E-212, E-215, and E-230 in this paper. Table 1 shows the chemical formula of these surfactants. The surfactants share the same chemical formula and differ in the polymerization degree of the ethylene oxide groups (E-230 > E-215 > E-212 $>$ E-205). Table 1 also shows the hydrophobic-lipophilic-balance (HLB) and melting point parameters of the surfactants. A numerically higher HLB indicates higher hydrophilicity, which is likely to result in an aqueous solution with a higher cloud point. The HLB listed in Table 1 was calculated by Griffin's method as expressed in Equation (1) [22]. The value of 20 corresponds to a completely hydrophilic/lipophobic molecule.

HLB $=20 \times$ sum of the molecular weight of the hydrophilic portions of the molecule/molecular weight

Table 1. The hydrophobic-lipophilic-balance (HLB) and melting point of surfactants.

\begin{tabular}{cccc}
\hline Product Name & Chemical Formula & HLB & $\begin{array}{c}\text { Melting Point }\left({ }^{\circ} \mathbf{C}\right) \\
\text { [23] }\end{array}$ \\
\hline Nonion E-205 & & 9.0 & 4 \\
Nonion E-212 & $\mathrm{C}_{18} \mathrm{H}_{35} \mathrm{O}\left(\mathrm{C}_{2} \mathrm{H}_{4} \mathrm{O}\right)_{n} \mathrm{H}$ & 13.3 & 31 \\
Nonion E-215 & & 14.2 & 35 \\
Nonion E-230 & & 16.6 & 40 \\
\hline
\end{tabular}

Then, transparent aqueous solutions were fabricated by dissolving the surfactants in ion-exchanged water to form a concentration of $20 \mathrm{wt} . \%$. In addition, DBTL (manufactured by Tokyo-Kasei Corporation, Tokyo, Japan) was added as a hydrophobic catalyst to these aqueous solutions to form a concentration of $2 \mathrm{wt} . \%$. After adding the DBTL, the aqueous solutions were heated at $60{ }^{\circ} \mathrm{C}$ and stirred at that temperature until the DBTL was uniformly dispersed.

\subsection{Paint Preparation}

Paints were prepared by blending the non-ionic surfactants described above with an acrylic emulsion and a polyisocyanate. The acrylic emulsion was synthesized to have a glass transition temperature of $20^{\circ} \mathrm{C}$ (estimated value by glass transition temperature of acrylic monomers) and a hydroxyl value of 150 (estimated value by glass transition temperature of acrylic monomers). Table 2 shows the monomer composition and the averaged molecular weight of the acrylic emulsion measured using gel permeation chromatography (GPC). A water-dispersible polyisocyanate was used (Burnock DNW5500 manufactured by DIC Corporation, Tokyo, Japan). The materials were blended to form a molar ratio of 1:1 between the acrylic emulsion hydroxyl groups and the isocyanate groups. In addition, the surfactant/DBTL aqueous solutions described above were added to the paint to form a DBTL concentration of $0.1 \mathrm{wt} . \%$. Then, the evaluation samples were finalized by adding an alkali thickener (Voncoat HV-E manufactured by DIC Corporation, Tokyo, Japan) and dimethylaminoethanol (manufactured by Wako Chemicals, Tokyo, Japan) as a neutralizer. In this paper, these samples are referred to as E205/DBTL, E212/DBTL, E215/DBTL, and E230/DBTL. Similarly, a sample without adding a surfactant/DBTL aqueous solution was also prepared. This is referred to below as the DBTL-free sample. This research also attempted to add the DBTL directly to the acrylic emulsion without adding a surfactant. However, because DBTL is hydrophobic, it was difficult to create a uniform dispersion. Therefore, the water content of the acrylic emulsion was removed in a vacuum-drying oven at room temperature. A sample was then prepared by adding Burnock DNW5500, 
acetone, and DBTL to the dried acrylic emulsion. The concentration of the DBTL in this paint sample was $0.1 \mathrm{wt} . \%$. This is referred to below as the directly added DBTL sample.

Table 2. Monomer composition and averaged molecular weight of acrylic emulsion.

\begin{tabular}{cc}
\hline Monomers & Blend Amount (wt.\%) \\
\hline Butyl acrylate & 22 \\
Butyl methacrylate & 19 \\
Methyl methacrylate & 10 \\
2-hydroxyethyl methacrylate & 36 \\
Styrene & 10 \\
Acrylic acid & 3 \\
Total & 100 \\
Averaged molecular weight & 11,500 \\
\hline
\end{tabular}

\subsection{Paint Evaluation}

\subsubsection{Measurement of Paint Curing Behavior}

The paints described in Section 2.2 were coated onto stainless-steel sheets (size: $40 \mathrm{~mm} \times 50 \mathrm{~mm}$, thickness: $0.5 \mathrm{~mm}$ ) and baked. The film thickness after baking was $35 \pm 5 \mu \mathrm{m}$. More specifically, the stainless-steel sheets were placed on a horizontal block. Adhesive tape (thickness: $70 \mu \mathrm{m}$ ) was attached to the stainless-steel sheets approximately $5 \mathrm{~mm}$ from the edges of two opposing sides. A knife with a straight cutting edge was run over the tape and the paint was coated in the gap between the stainless-steel sheet and the cutting edge of the knife.

After ten minutes the paint films were formed on the stainless-steel sheets using the paints described above, and the relative storage modulus ( $E^{\prime} r$ ) of the paint films was measured under a range of curing conditions from 60 to $140{ }^{\circ} \mathrm{C}$, set in $10^{\circ} \mathrm{C}$ increments. The measurements were taken using a rigid-body pendulum-type physical properties testing instrument (the RPT-5000 manufactured by A\&D Company, Ltd., Tokyo, Japan) equipped with an annular pendulum with a diameter of $74 \mathrm{~mm}$ and attached to a knife edge with a cutting angle of $40^{\circ}$. The temperature during measurement was programmed to increase by $20^{\circ} \mathrm{C}$ per minute from room temperature $\left(25^{\circ} \mathrm{C}\right)$ to the sintering temperature, and then to maintain the curing temperature. Measurement continued for at least $15 \mathrm{~min}$ after the inflection point described below.

The measured relative storage modulus ( $\left.E^{\prime} r\right)$ values were plotted against time. Over time, after initially forming a downwardly convex curve, the results formed an upwardly convex curve. The point at which this change occurred is referred to as the inflection point. The $15 \mathrm{~min}$ period from the inflection point was fitted in accordance with Equation (2) [24].

$$
E^{\prime} r=A[1-\exp \{k(t-t d)\}]
$$

where $\mathrm{A}$ is a constant, $\mathrm{k}$ is the curing speed constant, $\mathrm{t}$ is the time, and $\mathrm{td}$ is the curing start time.

$\mathrm{k}$ was calculated using the non-linear least squares method. Curing progresses faster as the $\mathrm{k}$ value increases.

\subsubsection{Evaluation of Paint Storage Stability}

The samples described above were exposed in an oven for $1 \mathrm{~h}$ at $40^{\circ} \mathrm{C}$. The viscosity of the paint before and after this period was measured using an ARES-G2 rheometer manufactured by TA Instruments Co. Ltd., Tokyo, Japan. The measurement conditions were as follows: temperature $=25.0 \pm 0.1^{\circ} \mathrm{C}$, shear rate $=1000 \mathrm{~s}^{-1}$, geometry $=$ cone plate with a diameter of $25 \mathrm{~mm}$, angle $=0.04 \mathrm{rad}$, and gap $=50 \mu \mathrm{m}$. It should be noted that the directly added DBTL sample was not measured since it gelified after exposure. 


\subsection{Measurement of Change in Molecular Weight of Micelles}

The change in molecular weight of the micelles was examined by SLS using a DLS8000 dynamic light-scattering spectrophotometer manufactured by Otsuka Electronics Co., Ltd., Osaka, Japan. The samples were prepared as follows. Transparent aqueous solutions were fabricated by dissolving E-212 and E-230 in deionized water to form a concentration of $20 \mathrm{wt} . \%$. DBTL was added as a curing catalyst to these aqueous solutions to form a concentration of $4 \mathrm{wt} . \%$. After adding the DBTL, the aqueous solutions were heated to $40{ }^{\circ} \mathrm{C}$ and stirred at that temperature until the curing catalyst was uniformly dispersed. Subsequently, deionized water was added to dilute the aqueous solutions and create surfactant concentrations of $0.025,0.050$, and $0.075 \mathrm{wt} . \%$. The deionized water was filtered in advance using a $0.1 \mu \mathrm{m}$ filter. Aqueous solutions with the same surfactant concentrations but without DBTL were also prepared for comparison.

Measurements were carried out under the following conditions. Measurement was carried out at a sequentially increasing temperature of $25,40,50,65$, and $78^{\circ} \mathrm{C}$. Then, the samples were radiantly cooled to $25^{\circ} \mathrm{C}$ and measured again. The measurement angle was set to $40,50,60,70,80,90,120$, and $150^{\circ}$. The measurement time was $16 \mathrm{~s}$. The integrated number of measurements was 100 and the number of repetitions was 1 .

Analysis was carried out from the scattering intensity data obtained at each concentration and angle using a square-root Zimm plot, and $\mathrm{M}_{\mathrm{W}}$ and $\mathrm{Rg}$ were calculated. It should be noted that the values obtained from the refractive index at each concentration, which was measured using a DRM-3000 highly sensitive differential refractometer (Otsuka Electronics Co., Ltd., Osaka, Japan, E-212/DBTL-free: 0.0282, E-230/DBTL-free: 0.0241, unit: mL/g), were used for the necessary $\mathrm{dn} / \mathrm{dC}$ component in the $\mathrm{M}_{\mathrm{W}}$ calculation. Although samples containing DBTL were not measured, the values would probably not be greatly different. Therefore, the respective DBTL-free values were used as-is. In addition, the refractive index (1.33) and viscosity $(0.89 \mathrm{mPa} \cdot \mathrm{s})$ of water at $25^{\circ} \mathrm{C}$ were used as the solvent conditions.

The following is known about the measurement of molecular weight using light scattering [16]. When spherical particles are exposed to perpendicular polarized light (wavelength $\lambda_{0}$, intensity $\mathrm{I}_{0}$ ), the SLS method used in this research has an observable scattered light intensity IS that can be expressed by Equation (3) [25].

$$
\frac{\mathrm{I}_{\mathrm{S}}}{\mathrm{I}_{0}}=\frac{4 \pi^{2} \mathrm{n}^{2} \mathrm{M}_{\mathrm{W}} \mathrm{C}(\mathrm{dn} / \mathrm{dC})^{2}}{\lambda_{0}^{4} \mathrm{r}^{2} \mathrm{~N}_{\mathrm{A}}}\left(1+\cos ^{2} \theta\right)
$$

where,

$\mathrm{n}$ : refractive index of solvent

$\mathrm{M}_{\mathrm{W}}$ : weight-average molecular weight

C: concentration of solute

$\mathrm{dn} / \mathrm{dC}$ : amount of concentration increases in refractive index difference

r: distance between light scattering substance and detection module

$\mathrm{N}_{\mathrm{A}}$ : Avogadro's number

Equation (4) [25] can be obtained by expressing Equation (3) using the optical constant $K$, the reduced scattering intensity $R(\theta)$, and the second virial coefficient (which expresses the interaction with the solvent) $\mathrm{A}_{2}$.

$$
\begin{gathered}
\frac{\mathrm{KC}}{\mathrm{R}(\theta)}=\frac{1}{\mathrm{M}_{\mathrm{W}}}+2 \mathrm{~A}_{2} \mathrm{C}+\cdots \\
\mathrm{K}=\frac{4 \pi^{2} \mathrm{n}^{2}(\mathrm{dn} / \mathrm{dC})^{2}}{\lambda_{0}^{4} \mathrm{~N}_{\mathrm{A}}}, \mathrm{R}(\theta)=\frac{\mathrm{r}^{2} \mathrm{I}_{\mathrm{S}}}{\mathrm{I}_{0}}\left(1+\cos ^{2} \theta\right)
\end{gathered}
$$

Based on Equation (4), if $K C / R(\theta)$ is plotted with respect to concentration, $M_{W}$ can be calculated from the reciprocal of the intersection extrapolated from $C$ to 0 , and $A_{2}$ can be calculated from the initial gradient. 
However, when the size of the particles exceeds $1 / 20$ of the wavelength of the incidence light, such as in the case of the surfactant micelles used in this experiment, interference occurs between the scattered light discharged from different parts of the particles. This creates a dependency between the intensity of scattering and the angle of incidence. Equation (5) is therefore expressed as follows:

$$
\begin{gathered}
\frac{K C}{R(\theta)}=\frac{1}{M_{W}}\left(1+\frac{1}{3} \operatorname{Rg}^{2} q^{2}+\cdots\right)+2 A_{2} C+\cdots \\
q=\frac{4 \pi n}{\lambda_{0}} \sin \left(\frac{\theta}{2}\right)
\end{gathered}
$$

where,

$\mathrm{Rg}^{2}$ : inertial square radius

q: scattering vector

Based on Equation (5) [25], if $[K C / R(\theta)]^{1 / 2}$ is plotted with respect to $\sin ^{2}(\theta / 2)$ (i.e., a squareroot Zimm plot), $\mathrm{M}_{\mathrm{W}}$ can be calculated from the reciprocal of the intersection double-extrapolated from $C$ to 0 and from $\theta$ to 0 , and $\mathrm{Rg}^{2}$ can be obtained from the gradient of the line that joins the $\mathrm{C}$ to 0 point of each concentration, thereby allowing the inertial radius $\mathrm{Rg}$ to be calculated.

\subsection{Evaluation of Dynamic Properties of Catalyst}

The samples were inserted into sample tubes with a diameter of $5 \mathrm{~mm}$. The JNMECA500 Fourier-transformation high-resolution nuclear magnetic resonance spectrometer (manufactured by JEOL Ltd., Tokyo, Japan) was used to examine the dynamics properties (motion) of the catalyst. Transparent aqueous solutions were fabricated by dissolving E-212 and E-230 in deuterium water to form a concentration of $20 \mathrm{wt} . \%$. DBTL (concentration: $2 \mathrm{wt} . \%$ ) was then added to these aqueous solutions and stirred until the curing catalyst was uniformly dispersed. Subsequently, deuterium water was added to dilute the aqueous solutions and create a surfactant concentration of $2.0 \mathrm{wt} . \%$. Measurement was carried out at a sequentially increasing temperature of room temperature $\left(24\right.$ to $\left.25^{\circ} \mathrm{C}\right), 30,40,50,60$, 70,80 , and $90^{\circ} \mathrm{C}\left(\mathrm{E}-212\right.$ only, E-230 was measured at 50 and $\left.70^{\circ} \mathrm{C}\right)$. The measured nucleus was ${ }^{1} \mathrm{H}(500 \mathrm{MHz})$, a single pulse measurement method was adopted, the delay time was $5 \mathrm{~s}$, and the integrated number of measurements was 16 .

\subsection{Measurement of Heat Flow of the Catalyst in the Surfactant Solution}

The Q-1000 Differential scanning calorimetry (manufactured by TA instrument Ltd., Tokyo, Japan) was used to examine the heat flow of catalyst in the surfactant solution. Transparent aqueous solutions were fabricated by dissolving E-212 and E-230 in deionized water to form a concentration of $2 \mathrm{wt} . \%$. DBTL (concentration: $0.2 \mathrm{wt} . \%$ ) was then added to these aqueous solutions and stirred until the curing catalyst was uniformly dispersed. Measurement was carried out at a sequentially increasing temperature from 20 to $85^{\circ} \mathrm{C}$ at a rate of $1{ }^{\circ} \mathrm{C} / \mathrm{min}$.

\section{Results and Discussion}

\subsection{Paint Curing Behavior}

Figures 2-5 show the relationship between $\mathrm{k}$ (the closed symbols in the figures) and the curing temperature for E205/DBTL, E212/DBTL, E215/DBTL, and E230/DBTL, respectively. Each figure also shows the $\mathrm{k} /$ curing temperature relationship of the DBTLfree sample (open triangle) and the directly added DBTL sample (open circle). Figure 2 confirms that $\mathrm{k}$ increases in accordance with the rise in curing temperature for both the DBTL-free and directly added DBTL samples. In addition, the $k$ value of the directly added DBTL sample is higher than that of the DBTL-free sample at any curing temperature. The $\mathrm{k}$ value of E205/DBTL is slightly lower than the $k$ value of the directly added DBTL sample at a temperature range between 70 and $80^{\circ} \mathrm{C}$. The values of E205/DBTL and the directly added DBTL are almost the same at $80{ }^{\circ} \mathrm{C}$ or higher. This is presumed to be the result 
of the micelles already starting to break down at a temperature of $70{ }^{\circ} \mathrm{C}$ or less, causing DBTL to be released and activating the catalytic function. Figure 3 shows the same results for E212/DBTL. Between 60 and $80^{\circ} \mathrm{C}$, the $\mathrm{k}$ value of E212/DBTL is substantially lower than the directly added DBTL sample. However, the $\mathrm{k}$ value increases rapidly from a temperature of $80^{\circ} \mathrm{C}$. Then, between 100 and $110^{\circ} \mathrm{C}$, the $\mathrm{k}$ value is virtually the same as that of the directly added DBTL sample. These results indicate the existence of gradual catalytic switching properties. This is presumed to be the result of most of the DBTL being constrained by the micelles at a temperature between 60 and $80^{\circ} \mathrm{C}$, before breaking down the micelles from a temperature of $80^{\circ} \mathrm{C}$, thereby activating the catalytic function. Figure 4 shows the same results for E215/DBTL. In the same way as Figure 3, these results indicate the existence of gradual catalytic switching properties. The $\mathrm{k}$ value of E215/DBTL at 100 ${ }^{\circ} \mathrm{C}$ is lower than that of the directly added DBTL sample. This suggests that the DBTL is still constrained by the micelles even at $100{ }^{\circ} \mathrm{C}$. Figure 5 shows the same results for E230/DBTL. Although the k value of E230/DBTL is slightly higher than the DBTL-free sample, no catalytic switching properties were confirmed. Therefore, this suggests that the DBTL in E-230 remains constrained by the micelles up to $130^{\circ} \mathrm{C}$. These results demonstrate that catalytic switching properties can be obtained using a surfactant with an HLB of between 13 and 14. The form and temperature changes of surfactant micelles are regarded as relevant factors behind the wide differences in the dependent relationship between $\mathrm{k}$ and curing temperature, which was observable depending on the type of surfactant. The form of the micelles in the surfactant/DBTL aqueous solutions was measured using static light scattering, the molecular motion characteristics of the DBTL were analyzed by measuring the NMR spectra, and the heat flow of DBTL in the surfactant solution by measuring the DSC. Hereinafter describes these measurements and discusses the results.

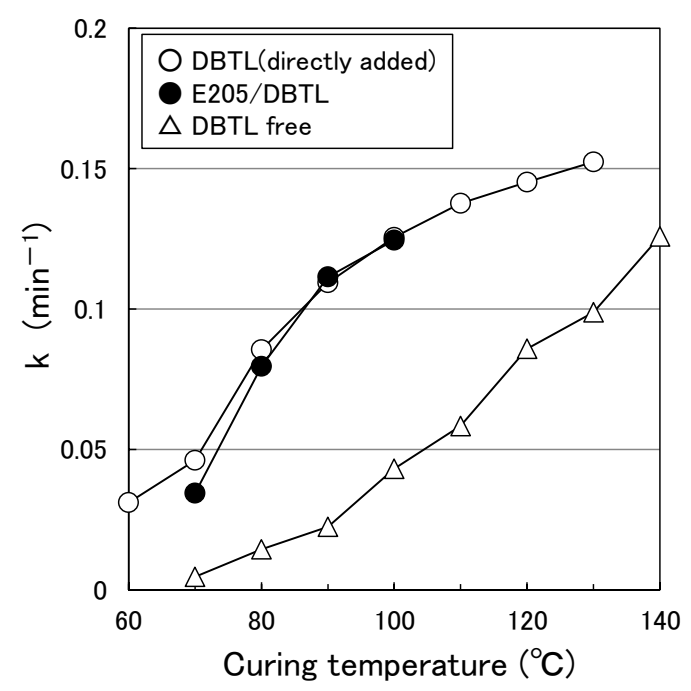

Figure 2. Relationship between the curing speed constant (k) and curing temperature (surfactant: E-205). 


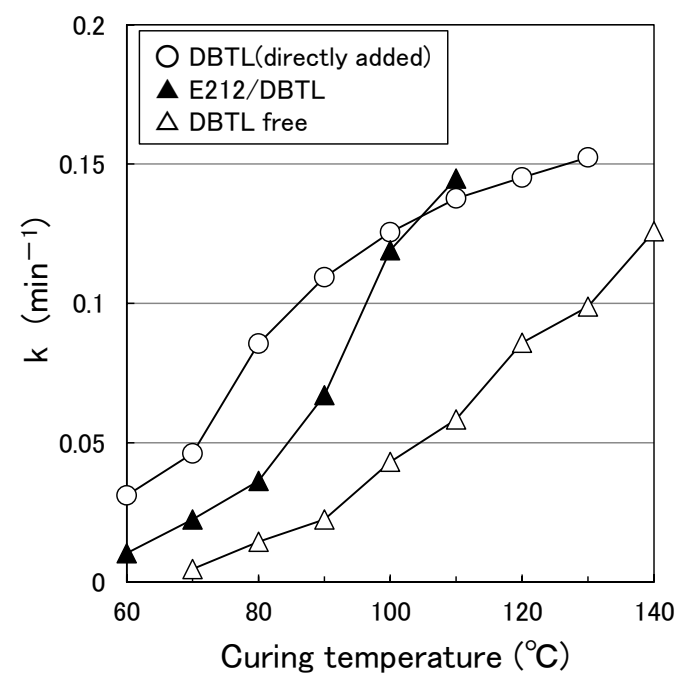

Figure 3. Relationship between k and curing temperature (surfactant: E-212).

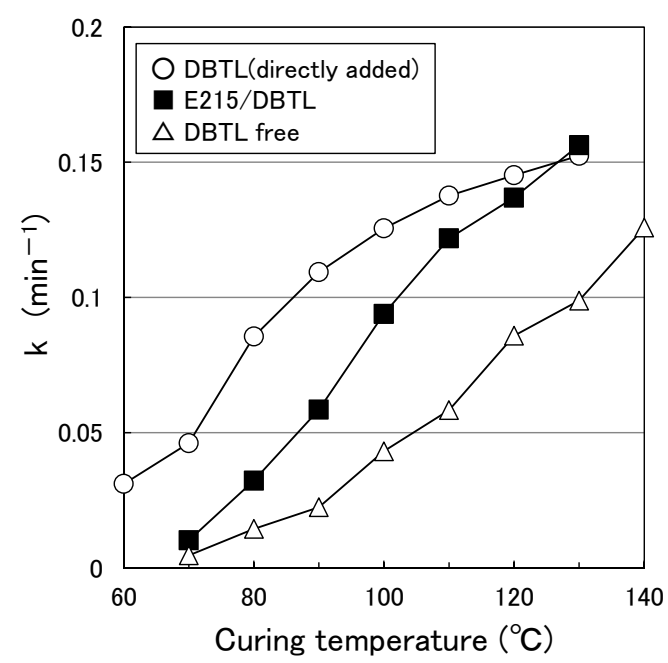

Figure 4. Relationship between k and curing temperature (surfactant: E-215).

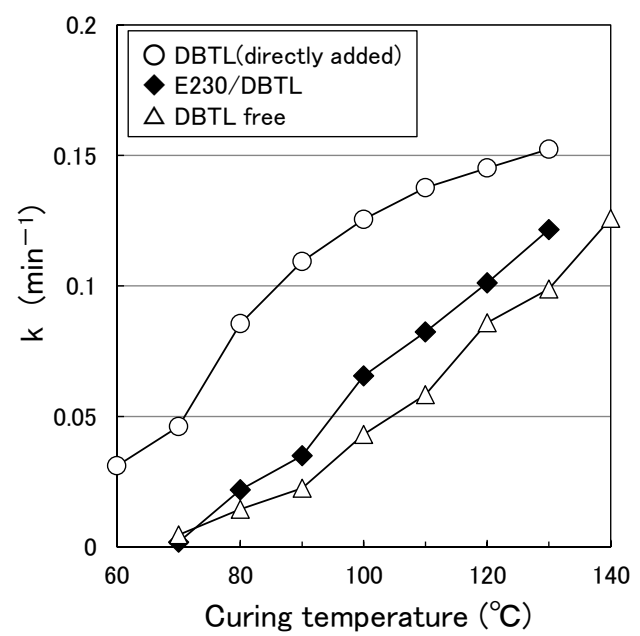

Figure 5. Relationship between $\mathrm{k}$ and curing temperature (surfactant: E-230).

\subsection{Paint Storage Stability}

Figure 6 shows the viscosity of E205/DBTL, E212/DBTL, E215/DBTL, and E230/DBTL at a shear rate of $1000 \mathrm{~s}^{-1}$ before and after exposure at $40{ }^{\circ} \mathrm{C}$ for $1 \mathrm{~h}$. The viscosity of 
E205/DBTL increased substantially after the exposure time. As described above, this is thought to be the result of the micelles already starting to break down at around $40{ }^{\circ} \mathrm{C}$, causing DBTL to be released and activating the catalytic function. For E212/DBTL, E215/DBTL, and E230/DBTL, the viscosity remained virtually unchanged after the exposure time. This is thought to be the result of most of the DBTL being constrained by the micelles, thereby preventing activation of the catalytic function.

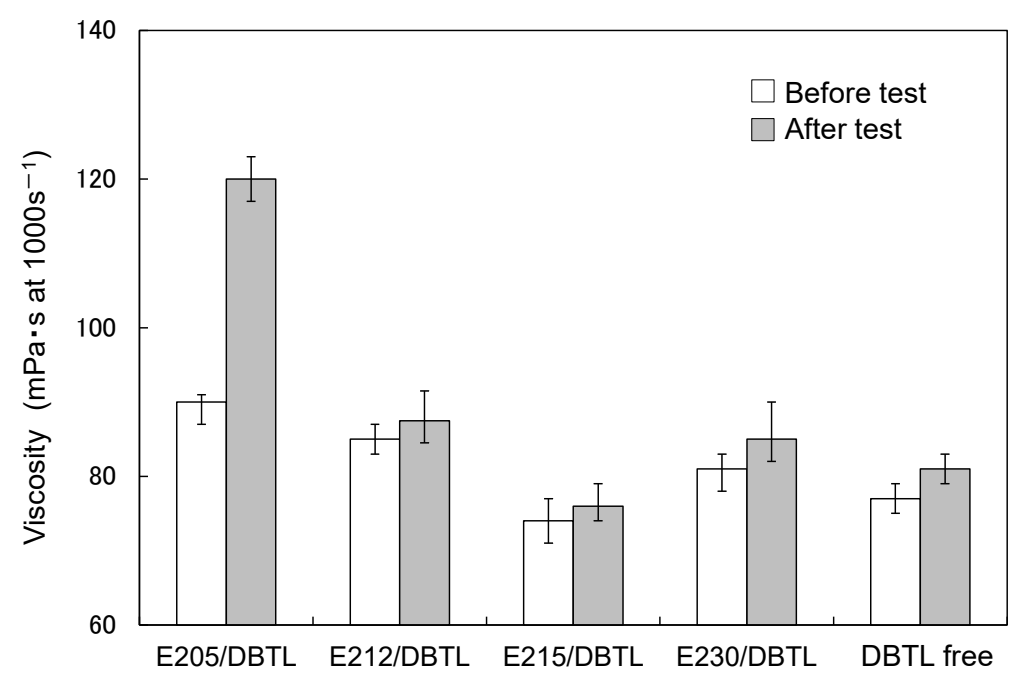

Figure 6. Storage stability of the waterborne paint with dibutyl tin dilaurate (DBTL) encapsulated in a micelle.

\subsection{Change in Molecular Weight of Micelles}

The relationship between the sample temperature and the $\mathrm{M}_{\mathrm{W}}$ and $\mathrm{Rg}$ values of E-212 and E-230 was evaluated using SLS. The $\mathrm{M}_{\mathrm{W}}$ and $\mathrm{Rg}$ values of aqueous solutions without added DBTL (the open circle and open triangle in Figures 7 and 8) increased steadily in accordance with the rise in the sample temperature. As described above, it is thought that the $\mathrm{M}_{\mathrm{W}}$ and $\mathrm{Rg}$ values will increase as the micelles become larger. Therefore, this result suggests that the hydrophobic interaction of the surfactant molecules intensifies as the temperature increases, thereby resulting in micelle growth. For E-212 and E-230, the aqueous solutions containing added DBTL (closed circle and closed triangle in Figures 7 and 8), the $\mathrm{M}_{W}$ and $\mathrm{Rg}$ values were higher than the aqueous solutions without DBTL at all temperatures. This is presumed to be the result of the DBTL being contained by the micelles. As the temperature increased, the $\mathrm{M}_{\mathrm{W}}$ and $\mathrm{Rg}$ values of the aqueous solutions containing DBTL reached a peak at 40 and $65^{\circ} \mathrm{C}$, respectively. As mentioned above, the increase in the $\mathrm{M}_{\mathrm{W}}$ and $\mathrm{Rg}$ values up to the peaks as the temperature increased is probably due to the intensification in the hydrophobic interaction of the surfactant molecules, which results in micelle growth. Therefore, the fall in the $\mathrm{M}_{\mathrm{W}}$ and $\mathrm{Rg}$ values after the peaks as the temperature increased is probably due to a reduction in the size of the micelles. However, the reasons for this decrease are not evident from these results. Next, the $\mathrm{M}_{\mathrm{W}}$ and $\mathrm{Rg}$ values of the E-212 aqueous solution containing DBTL were measured again after radiant cooling from 65 to $25^{\circ} \mathrm{C}$. The value at $25^{\circ} \mathrm{C}$ was virtually the same as at $65{ }^{\circ} \mathrm{C}$, but substantially lower than the value originally measured at $25^{\circ} \mathrm{C}$ (Figures 9 and 10). These results suggest that one reason for the decrease in the $\mathrm{M}_{\mathrm{W}}$ and $\mathrm{Rg}$ values at temperatures after the peak is a reduction in the size of the micelles due to DBTL discharge. However, it is difficult to judge the accuracy of that assumption since the $\mathrm{M}_{\mathrm{W}}$ and Rg values may have decreased while still including the DBTL. Another possible reason for the difference in the $\mathrm{M}_{\mathrm{W}}$ and $\mathrm{Rg}$ values at $25^{\circ} \mathrm{C}$ before and after heating is as follows. It is possible that after being discharged, the DBTL is not re-incorporated into the micelles after radiant cooling to $25^{\circ} \mathrm{C}$ but exists independently in the aqueous solution. In this case, it should be possible to confirm the presence of independent DBTL as oil drops in the aqueous solution since DBTL 
is insoluble in water. However, since the concentration of the DBTL in the measurement sample was only $0.005 \mathrm{wt} . \%$, these drops may not be readily observable.

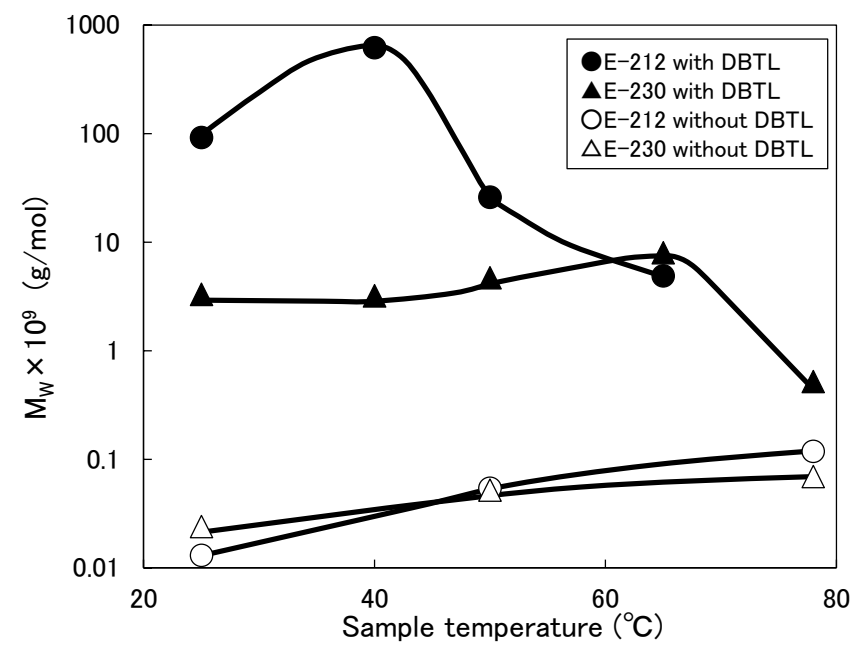

Figure 7. Relationship between sample temperature and weight-average molecular weight $\left(\mathrm{M}_{\mathrm{W}}\right)$ (surfactant: E-212 and E-230 with or without DBTL).

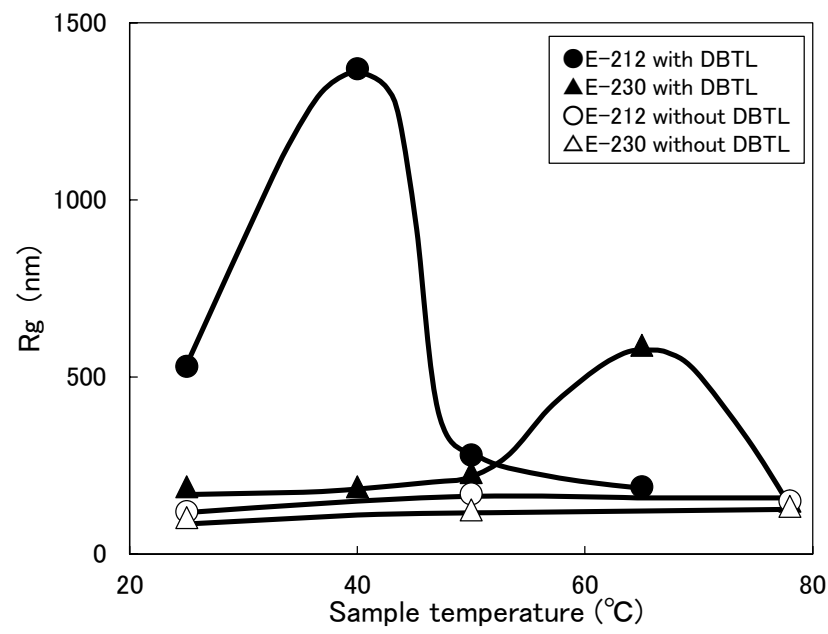

Figure 8. Relationship between sample temperature and inertial radius (Rg) (surfactant: E-212 and E-230 with or without DBTL).

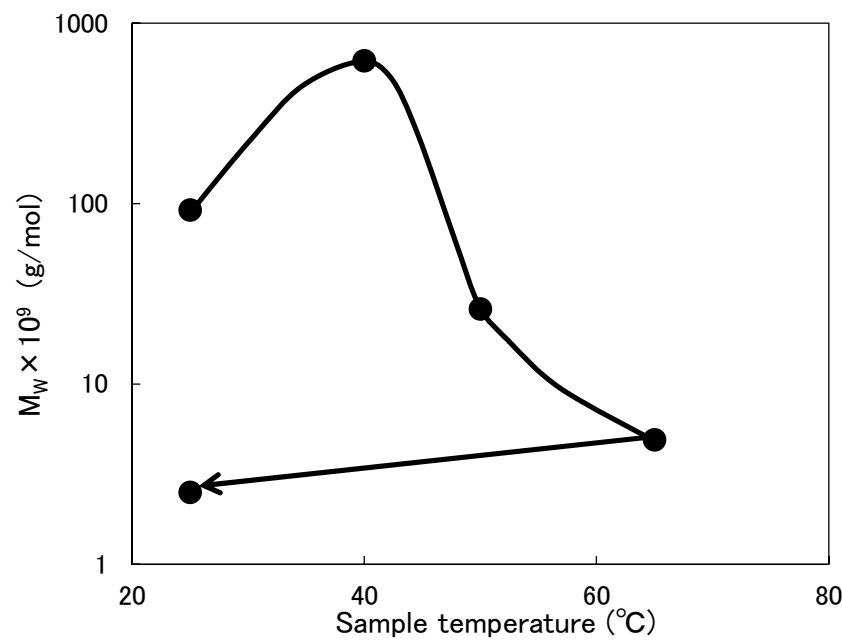

Figure 9. Relationship between sample temperature and $\mathrm{M}_{\mathrm{W}}$ (surfactant: E-212 with DBTL). 


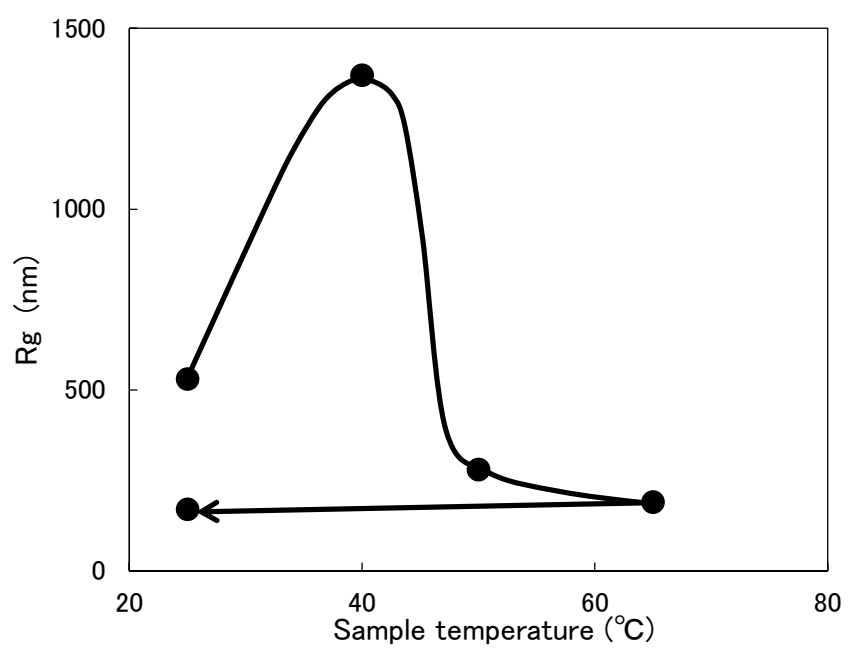

Figure 10. Relationship between sample temperature and $\operatorname{Rg}$ (surfactant: E-212 with DBTL).

\subsection{Dynamic Properties of Catalyst}

Figure 11 shows a part of the ${ }^{1} \mathrm{H}-\mathrm{NMR}$ spectrum when the E-212 aqueous solution containing DBTL was heated from room temperature $\left(24\right.$ to $\left.25^{\circ} \mathrm{C}\right)$ to $90{ }^{\circ} \mathrm{C}$. This spectrum shows a peak derived from the $\mathrm{C}(=\mathrm{O}) \mathrm{CH}_{2}$ group of the DBTL. However, this peak is not distinct between room temperature and $40{ }^{\circ} \mathrm{C}$, and only becomes noticeable at a temperature of $50{ }^{\circ} \mathrm{C}$ or higher. This result suggests that the DBTL molecular motion is constrained by the surfactant molecules (micelles) between room temperature and 40 ${ }^{\circ} \mathrm{C}$, and that the DBTL molecules become less susceptible to such constraints at $50{ }^{\circ} \mathrm{C}$ or higher. The temperature at which this molecular motion becomes less susceptible to constraint is around $40{ }^{\circ} \mathrm{C}$, i.e., the temperature at which the peak $\mathrm{M}_{\mathrm{W}}$ and $\mathrm{Rg}$ values were obtained in Figures 7 and 8. As described in Section 3.3, this is presumed to be because the DBTL is discharged from the micelles at the peak $\mathrm{M}_{\mathrm{W}}$ and $\mathrm{Rg}$ temperature. Next, Figures 12 and 13 compare the spectra for E-212 and E-230 (both containing DBTL) at 50 and 70 ${ }^{\circ} \mathrm{C}$, respectively. Figure 12 shows a clear DBTL-derived $\mathrm{C}(=\mathrm{O}) \mathrm{CH}_{2}$ group peak for E-212 (the upper spectrum in Figure 12). In contrast, the peak for E-230 contains a shoulder and is slightly less distinct (the lower spectrum in Figure 12). One reason for this may be as follows. Considering the different peak $\mathrm{M}_{\mathrm{W}}$ and $\mathrm{Rg}$ temperatures for E-212 and E-230 in Figures 7 and 8, most of the DBTL has probably been discharged from the micelles at $50{ }^{\circ} \mathrm{C}$ in the case of E-212. However, at the same temperature, almost all of the DBTL probably remains constrained by the micelles in the case of E-230. However, it is difficult to make a definite judgement. In contrast, Figure 13 shows clear $\mathrm{C}(=\mathrm{O}) \mathrm{CH}_{2}$ group peaks for both E-212 and E-230. This is probably because most of the DBTL has been discharged from the micelles at $70{ }^{\circ} \mathrm{C}$ in the case of both samples.

\subsection{Heat Flow of Catalyst in the Surfactant Solution}

Figures 14 and 15 show the DSC profiles when the E-212 and the E-230 aqueous solutions containing DBTL were heated from 20 to $85^{\circ} \mathrm{C}$, respectively. Figure 14 shows that the heat flow is constant from $25^{\circ} \mathrm{C}$ and decreases as temperature increases from $60{ }^{\circ} \mathrm{C}$ for the E-212 solution without DBTL and decreases from $30{ }^{\circ} \mathrm{C}$ for the E-212 solution with DBTL. Figure 15 also shows that the heat flow is almost constant as temperature increases up to $85{ }^{\circ} \mathrm{C}$ for the E-230 solution without DBTL, and that the heat flow decreases as temperature increases from $50{ }^{\circ} \mathrm{C}$ for the E-230 solution with DBTL. These results indicate that the micelle structure changes with increasing temperature, and the change point shifts to the low temperature side with the addition of the catalyst. These results also support results suggesting a relationship between $\mathrm{M}_{\mathrm{W}} / \mathrm{Rg}$ and temperature, as shown in Figures 7 and 8 . 


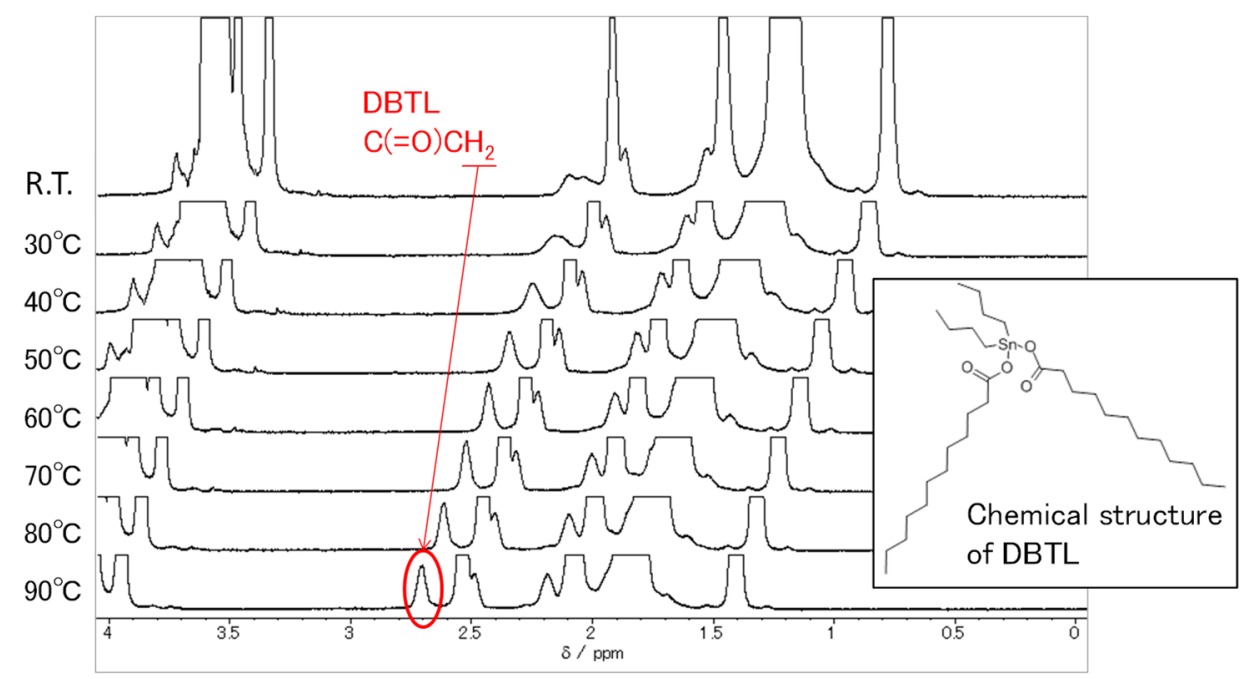

Figure 11. ${ }^{1} \mathrm{H}-\mathrm{NMR}$ spectrum (E-212 with DBTL) at changing sample temperature.

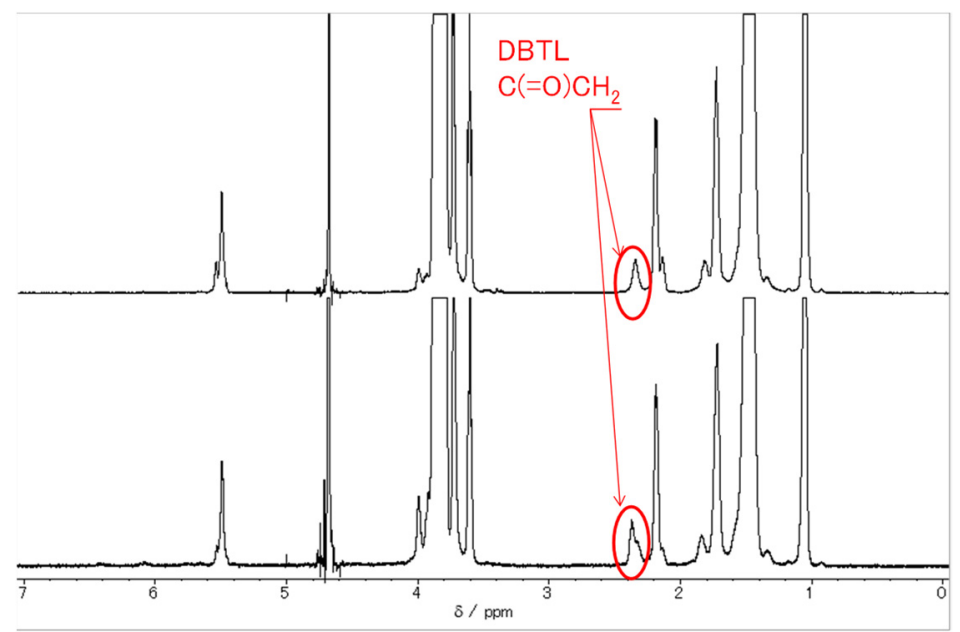

Figure 12. ${ }^{1} \mathrm{H}-\mathrm{NMR}$ spectrum comparison of E212/DBTL (upper) and E230/DBTL (lower) at $50{ }^{\circ} \mathrm{C}$.

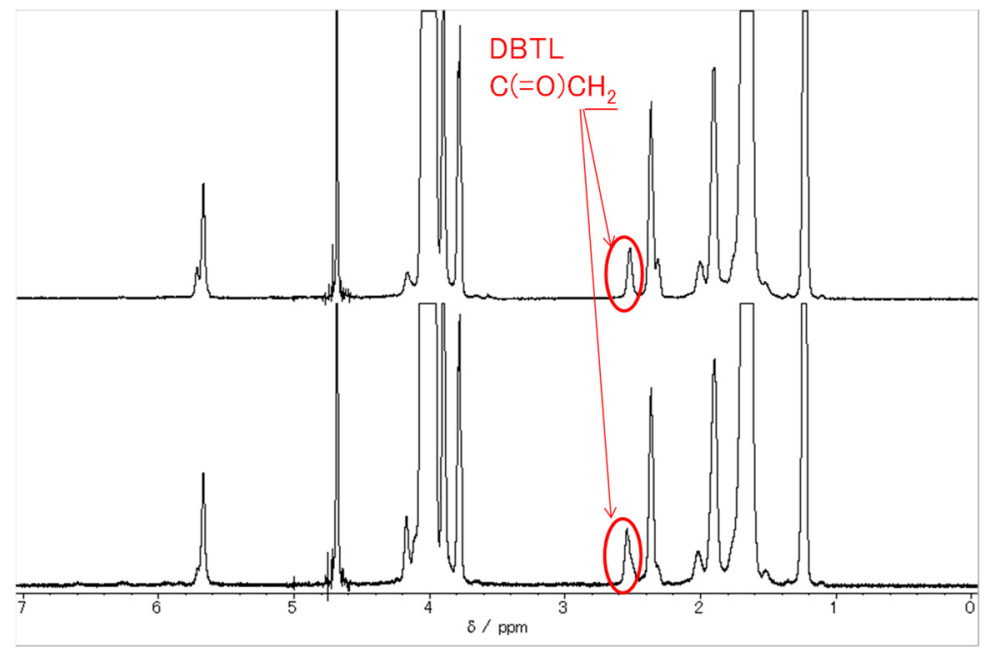

Figure 13. ${ }^{1} \mathrm{H}-\mathrm{NMR}$ spectrum comparison of E212/DBTL (upper) and E230/DBTL (lower) at $70{ }^{\circ} \mathrm{C}$. 


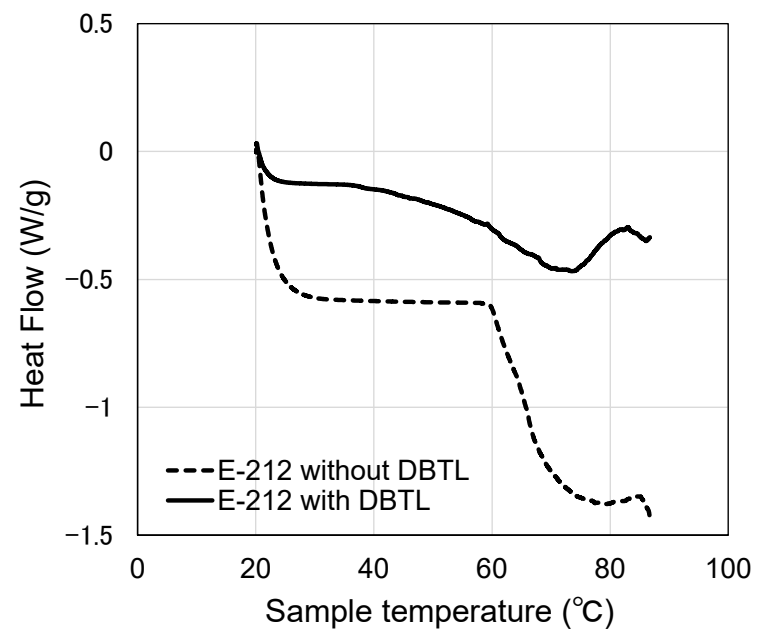

Figure 14. Differential scanning calorimetry (DSC) profile of the E-212 solution with or without DBTL.

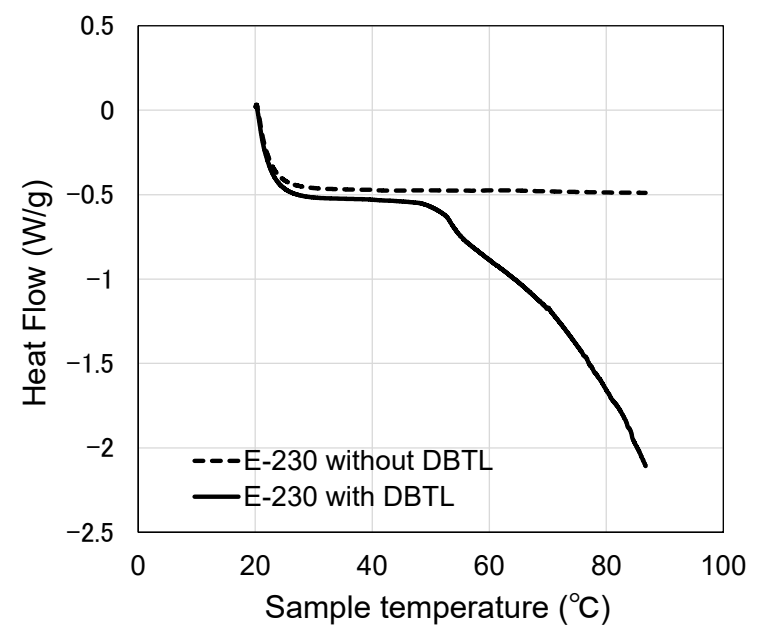

Figure 15. DSC profile of the E-230 solution with or without DBTL.

\subsection{Effect of HLB of the Surfactant on Curing Behavior}

Summarizing the results described above, the catalytic switching properties may be thought to occur as follows:

- $\quad$ Adding DBTL to a non-ionic surfactant aqueous solution increases $\mathrm{M}_{\mathrm{W}}$ and Rg values. One reason for this is because the DBTL molecules are constrained by the surfactant molecules (micelles). Since DBTL is highly hydrophobic, the hydrophobic portions of the surfactant molecules are more likely to be incorporated into the inwardly oriented micelles (Figure 1).

- Although the micelles grow as the temperature increases, the peak temperature for E-212 is $40{ }^{\circ} \mathrm{C}$ and the peak temperature for E-230 is $65^{\circ} \mathrm{C}$. At temperatures above these peaks, the $\mathrm{M}_{\mathrm{W}}$ and $\mathrm{Rg}$ values decrease. One reason for this is thought to be the gradual discharge of DBTL from the micelles, since the micelles start to break down at $40{ }^{\circ} \mathrm{C}$ or higher for E-212 and at $65^{\circ} \mathrm{C}$ or higher for E-230.

- The switching function starting temperature based on the measured viscoelasticity results for the paint films (E-212: $80^{\circ} \mathrm{C}, \mathrm{E}-230: 120^{\circ} \mathrm{C}$ or higher) is different in absolute terms from the results described in (2). As the former results were obtained from paint films with an extremely low water content, the motion of the DBTL molecules was also low. In contrast, as the latter results were obtained using aqueous solutions, the motion of the DBTL molecules was higher. This difference in motion is likely reflected in this absolute temperature difference. 


\section{Conclusions}

Aqueous solutions consisting of DBTL added to non-ionic surfactant micelles were prepared and added to isocyanate curable waterborne paints. Then, this research examined whether the added DBTL provided a switchable catalytic function for curing the waterborne paint that activates at $80^{\circ} \mathrm{C}$ or higher. It was confirmed that the use of a non-ionic surfactant with an HLB of between 13 and 14 resulted in rapid curing at a temperature of $80^{\circ} \mathrm{C}$ or higher. The results also found that the viscosity of the paint remained virtually unchanged after exposure for $1 \mathrm{~h}$ at $40^{\circ} \mathrm{C}$. This is presumed to be the result of the DBTL, which was constrained by the micelles up to a temperature of $70{ }^{\circ} \mathrm{C}$, breaking down the micelles at a temperature of $80^{\circ} \mathrm{C}$ or higher, thereby activating the catalytic function. It was also confirmed that the catalytic switching properties were not obtained at a lower or higher HLB. This research also examined changes in the molecular weight of the micelles caused by adding the catalyst using SLS, and the molecular motion of the catalyst in the surfactant aqueous solution using NMR and heat flow of the catalyst in the surfactant solution using DSC. The mechanism of the catalytic function was studied based on these results. Although the micelles grow as the temperature increases, the micelles gradually break down after growth peaks at $40^{\circ} \mathrm{C}$ in the case of micelles with catalytic switching properties (E-212, $\mathrm{HLB}=13$ to 14 ), and after growth peaks at $65^{\circ} \mathrm{C}$ in the case of micelles with weak catalytic switching properties (E-230).

Funding: This research received no external funding.

Institutional Review Board Statement: Not Applicable.

Informed Consent Statement: Not Applicable.

Data Availability Statement: Data sharing is not applicable for this article.

Acknowledgments: The author would like to express their sincere gratitude to Hiroshi Nakamura and Makoto Mouri of the Toyota Central R\&D Labs, Inc. for their useful discussions and guidance in preparing this manuscript.

Conflicts of Interest: The author declares no conflict of interest.

\section{References}

1. Bailey, M.E.; Kirss, V.; Spaunburgh, R.G. Reactivity of Organic Isocyanates. Ind. Eng. Chem. 1956, 48, 794. [CrossRef]

2. Wicks, D.A.; Wicks, Z.W., Jr. Blocked isocyanates III Part B: Uses and applications of blocked isocyanates. Prog. Org. Coat. 2001, 41, 1-83. [CrossRef]

3. Modi, S.; Spubler, A.; Jin, J. Impact of Automated, Connected, Electric, and Shared (ACES) Vehicles on Design, Materials, Manufacturing and Business Models; Center for Automotive Research: Ann Arbor, MI, USA, 2018.

4. Melchiors, M.; Sonntag, M.; Kobusch, C.; Juergens, E. Recent developments in aqueous two-component polyurethane (2K-PUR) coatings. Prog. Org. Coat. 2020, 40, 99-109. [CrossRef]

5. Yomo, S.; Tachi, K.; Narita, T. Improving the appearance of 3-coat-l-bake multilayer films on automotive bodies. Prog. Org. Coat. 2018, 123, 299. [CrossRef]

6. Wicks, D.A.; Wicks, Z.W., Jr. Blocked isocyanates III: Part A. Mechanisms and chemistry. Prog. Org. Coat. 1999, 36, 148-172. [CrossRef]

7. Cram, D.J.; Cram, J.M. Monographs in Supramolecular Chemistry; The Royal Society of Chemistry: Cambridge, UK, 1994; Volume 4, p. 223.

8. June, Y.G.; Jung, K.I.; Choi, M.; Lee, T.H.; Noh, S.M.; Jung, H.W. Effect of Urethane Crosslinking by Blocked Isocyanates with Pyrazole-Based Blocking Agents on Rheological and Mechanical Performance of Clearcoats. Coatings 2020, 10, 961. [CrossRef]

9. Wang, L.; Zou, H.; Dong, Z.; Zhou, L.; Li, J.; Luo, Q.; Zhu, J.; Xu, J.; Liu, J. Temperature-Driven Switching of the Catalytic Activity of Artificial Glutathione Peroxidase by the Shape Transition between the Nanotubes and Vesicle-like Structures. Langmuir 2014, 30, 4013-4018. [CrossRef] [PubMed]

10. Kremer, C.; Schnakenburg, G.; Lutzen, A. Towards allosteric receptors-Synthesis of beta-cyclodextrin-functionalised 2,2'bipyridines and their metal complexes. Beilstein J. Org. Chem. 2014, 10, 814-824. [CrossRef] [PubMed]

11. Zhu, X.; Xu, G.; Chamoreau, L.; Zhang, Y.; Mouries-Mansuy, V.; Fensterbank, L.; Bistri-Aslanoff, O.; Roland, S.; Sollogoub, M. Permethylated NHC-Capped alpha- and beta-Cyclodextrins (ICyDMe) Regioselective and Enantioselective Gold-Catalysis in Pure Water. Chem. Eur. J. 2020, 26, 15901-15909. 
12. Quach, Q.; Biehler, E.; Elzamzami, A.; Huff, C.; Long, J.L.M.; Abdei-Fattah, T.M. Catalytic Activity of Beta-Cyclodextrin-Gold Nanoparticles Network in Hydrogen Evolution Reaction. Catalysts 2021, 11, 118. [CrossRef]

13. Ye, R.P.; Lin, L.; Liu, C.Q.; Chen, C.C.; Yao, Y.G. One-Pot Synthesis of Cyclodextrin-Doped Cu-SiO2 Catalysts for Efficient Hydrogenation of Dimethyl Oxalate to Ethylene Glycol. Chemcatchem 2017, 9, 4587-4597. [CrossRef]

14. Ikeda, A.; Shinkai, S. Novel cavity design using calix[ $n]$ arene skeletons: Toward molecular recognition and metal binding. Chem. Rev. 1997, 97, 1713-1734. [CrossRef] [PubMed]

15. Duchene, D. New Trends in Cyclodextrins and Derivatives; Edition de Sante: Paris, France, 1991; p. 449.

16. Vaution, C. Cyclodextrins and Their Industrial Uses; Edition de Sante: Paris, France, 1987; p. 297.

17. Kiasat, A.R.; Saghanezhad, S.J.; Noori, S. Beta-Cyclodextrin Based Nanosponges in Organic Synthesis. Curr. Org. Chem. 2019, 23, 2366-2377. [CrossRef]

18. Mori, K.; Yamashita, H. Design of Colloidal and Supported Metal Nanoparticles: Their Synthesis, Characterization, and Catalytic Application. J. Jpn. Pet. Inst. 2011, 54, 1-14. [CrossRef]

19. Szejtli, J. Cyclodextrins in food, cosmetics, and toiletries. Starch/Staerke 1982, 34, 379. [CrossRef]

20. Hinze, W.L.; Pramauro, E. A critical-review of surfactant-mediated phase separations (cloud-point extractions)—Theory and applications. Crit. Rev. Anal. Chem. 1993, 24, 133-177. [CrossRef]

21. Miller, C.A.; Raney, K.H. Solubilization emulsification mechanisms of detergency. Colloids and Surf. A-Physicochem. Eng. Asp. 1993, 74, 169. [CrossRef]

22. Brown, W.; Schillen, K.; Almgren, M.; Hvidt, S.; Bahadur, P. Micelle and gel formation in a poly(ethylene oxide) poly(propylene oxide) poly(ethylene oxide) triblock copolymer in water solution-Dynamic and static light-scattering and oscillatory shear measurements. J. Phys. Chem. 1991, 95, 1850-1858. [CrossRef]

23. NOF. Corporation Products Catalogue. Available online: https://www.nof.co.jp/business/oleo/pdf/comprehensive.pdf (accessed on 18 January 2021). (In Japanese).

24. Mori, K. Method for Estimating Crosslink Density in Curing Process on Coating Films-Proportionality between Storage Modulus and Crosslink Density. J. Jpn. Soc. Color Mater. 2013, 86, 123. [CrossRef]

25. Zimm, B.H. The Scattering of Light and the Radial Distribution Function of High Polymer Solutions. J. Chem. Phys. 1948, 16, 1093-1099. [CrossRef] 